\title{
A Three-dimensional Analysis Model and Application about Energy Conservation\& Emissions Reduction Technology System and Synergistic effect of an Energy Intensive Product
}

\author{
Jiliang Zheng and Qingqing Gu \\ Faculty of Management \& Economics, Kunming University of Science \& Technology, Kunming China
}

\begin{abstract}
It is an important project to improve the synergistic effect of energy conservation \&emissions reduction (ECER) through building technical system now. Energy intensive products are the key to promote ECER strategy in China. It is necessary to study the relationship between the construction of technology system and synergistic effect of ECER. Thus, this paper built a three-dimensional model to analyze ECER technology system and synergistic effect in production of a product by the analysis method of value flow and Euclidean space coordinate system. With an energy intensive product as example, this paper used the model to analyze the ECER synergistic effect of technology system in each stage of production. The results show that the three-dimensional analysis model has a certain value of theoretical and practical application for further studying the construction of the technology system and synergistic effect of ECER of energy intensive products.
\end{abstract}

\section{Introduction}

There were some researches on the relationship between technology system and synergistic effect of energy conservation \&emissions reduction (ECER) in manufacturing industry so far. The representative research has the following. Martin(2015) selected 22 ECER measures in the iron and steel industry to evaluate and compare the emission reduction potential and cost as well as synergistic effect of each measure. Mao Xianqiang(2012) proposed a method to evaluate the synergistic control effect of technical reduction measures on sulfur, nitrogen and carbon in iron and steel industry, and examined the synergistic control effect of different measures from multi angle. Xing Fangfang(2013) analyzed the characteristics of synergistic control technology about sintering flue gas multi pollutant in iron and steel industry in China and abroad, and made a comparative analysis on the technical economy and emission reduction effect. Zhu Guilin (2010) proved that the technology innovation of comprehensive utilization of steel slag had improved significantly the ECER effect of the iron and steel industry based on 2005-2010 data. Han Yijie(2011) found that technological innovation is the endogenous mechanism of ECER and has a positive effect on ECER performance through researching on energy efficiency and ECER potential of iron and steel industry. Zeng Ping (2013) got a conclusion that ECER technology innovation of enterprises has a significant stimulating role, and the enterprises of advanced energy-conservation or reaching to discharge standards have higher new product output rate through research and empirical analysis on 348 manufacturing enterprises in Guangdong Pearl River Delta.

International research on this area is less. Most of the related research was done by Chinese scholars to discuss the issue of ECER in Chinese enterprises or industries in international journals. Representative papers have the following. $\mathrm{Li}$ Li (2011) researched on ECER policies in China's electric power industry. Zhang Zhaoguo (2013) studied the influence factors of ECER in China's listed companies. Yan Gao (2011) evaluated the effect of energy conservation and pollutant emission reduction of the coal mine enterprise. Pimenteira (2004) researched on energy conservation and carbon emission reduction by recycling in Brazil. It is seen that the research on the relationship between technology system and synergistic effect of ECER is rare from micro perspective of an energy intensive product so far. Therefore, in this paper, the theory and application of ECER of an energy intensive product was studied by using two dimensional or three dimensional coordinate system analysis and value flow analysis methods on the aspect of energy intensive product. This paper tries to constructs a 3D model, and to demonstrate the rationality of the model through the application on a case. It will provide a micro level of theoretical guidance and practical analysis method to promote ECER progress of energy intensive products, and so as to enrich the related theory system.

\section{A three-dimensional analysis models about ecer technology system and synergistic effect of an energy intensive product}


The ECER technology system of an energy intensive product refers to the integration of energy conservation technology, emissions reduction technology, waste recycling technology, and the scale production of by-products in production. The technical synergistic effect of an energy intensive product refers to the integrated ECER effect generated through the integrated application of a technology system in the production of products. The ECER synergistic effect of a product may be measured through value flow analysis. From perspective of circular economy of "resource value" concept, value flow describes the value change of material flow in the circular motion by means of accounting theory and material flow route (Lin Yanyu, 2013). The purpose of technology system construction of an energy intensive product is to promote the most efficient use of resources and maximize the recycling of waste products in the production and operation of energy intensive products. It requires each product to minimize the resources consumption and waste emission to obtain the maximum comprehensive benefits from the input of resources, resource recycling to the output of the resources.

In the whole process of production, ECER synergies of technologies may be divided into two situations as below. First, a single technology may improve energy conservation or emissions reduction effects simultaneously of a product, which is called as the single technical synergistic effect here. Second, the integration of technologies improves a product's ECER effect, which is called as the inter-technology synergy effect. The integrative synergistic effects of both single technology and inter-technology come to the total synergistic effects of a technology system.

\subsection{Analysis models of synergistic effect on a single technology and inter-technology}

In the two-dimensional Euclidean space coordinate system, the ordinate represents energy conservation effect, abscissa represents emission reduction effect. Each technology position in coordinate system shows the comprehensive effect of a technology, which was referred to ECER synergistic effect (Mao Xianqiang, 2011), as shown in Figure 1. The synergistic effect of inter-technology refers to meet the requirements of ECER targets through the space distribution of a number of technologies.

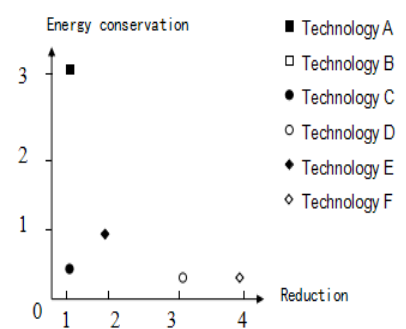

Figure 1. ECER synergistic effect of a single technology

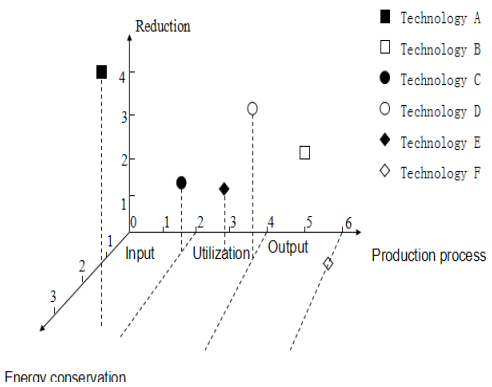

Figure 2. Three-dimensional map of ECER synergy effects of production technology system

\subsection{A three dimensional analysis model on synergistic effect of a product's technology system}

A product production is a process of integration applications of a number of technologies. Production process may be divided into three stages generally: resource input, resource utilization and resource output stage. Each stage involves the application of ECER technologies. The integration of all technologies forms a product's technology system. Therefore, the three-dimensional Euclidean space coordinate system may be used to express the three-dimensional relationship between the production process and ECER effect, as shown in figure 2 .

\subsection{Reference standard for collaborative evaluation of technical system}

According to the cooperative type of single technology and inter-technology, the collaborative evaluation reference standard of a technical system is designed as shown in Table 1.

Table 1. Reference standard for technical collaborative evaluation

\begin{tabular}{|c|c|c|}
\hline NO. & Judging index & Reference standard for judging result \\
\hline 1 & $\begin{array}{c}\text { More than a type of synergy, whether there is a } \\
\text { technical synergy is OK. }\end{array}$ & Good synergy \\
\hline 2 & A type of synergy + inter-technology synergy & General synergy \\
\hline 3 & A type of synergy and no inter-technology synergy & Poor synergy \\
\hline
\end{tabular}




\subsection{A value flow analysis model on ECER synergistic effect in a product's technology system}

It is suitable to use value flow method to evaluate and sum the value flow produced by ECER technology system to obtain the comprehensive effects or synergistic effects of a product as shown in Figure 3. The value flows in Figure 3 indicate the economic effect of ECER after applying a certain technology, including reducing the consumption of energy and raw materials, or reducing the disposal cost of waste and pollution. The sum of the value added in the whole production is the comprehensive effect of ECER, which is produced by the synergy in technology system. If a synergistic effect may be formed between technologies, it will achieve the optimization of ECER effects and even the maximization. Figure 3 expresses not only the application scope of ECER technology, and also considerate waste utilization and optimization in product production.

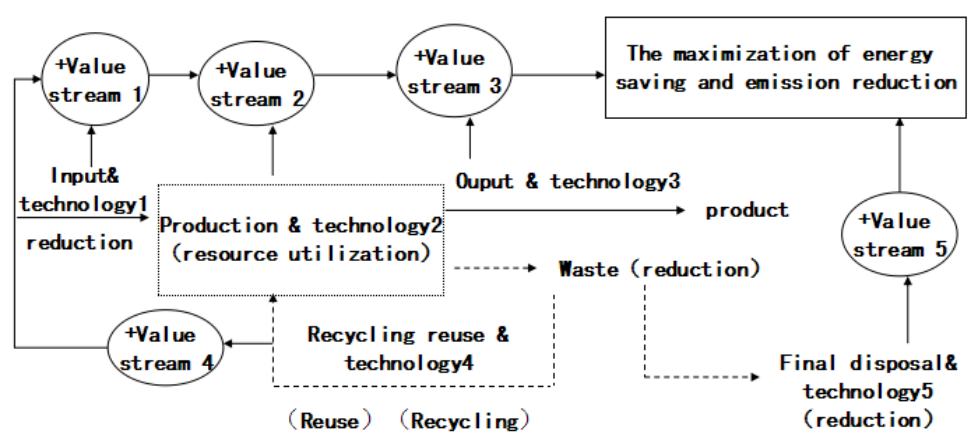

Figure 3. A value flow analysis model of ECER synergistic effects in a product's technology system

\section{Case study of an energy intensive product}

\subsection{Product introduction}

Take a PVC product of a chemical firm as an example to analyze the ECER effect produced by the construction of technology system. Polyvinyl chloride (PVC) is a kind of widely used plastic. Owing to energy intensive production and serious pollution, the calcium carbide process is one to eliminate in the world. However, due to the situation of lack oil and gas, as well as maturity technology and less investment, it provides a greater market space for the calcium carbide acetylene process with coal as raw material. This firm has taken a series of technical measures on the PVC product to improve cleaner production, energy conservation and emission reduction in order to ensure the normal operation of the firm.

\subsection{Process flow analysis}

Using local lignite coal, the firm produces steam for the use of caustic soda and PVC production, waste heat is used to generate electricity which is called cogeneration. It produces PVC resin by using chlorine and hydrogen by-products from production of caustic soda as well as calcium carbide raw material. The calcium carbide slag produced in the process of polyvinyl chloride production is calcined and decomposed into cement clinker, mixed with the fly ash produced from thermoelectric boiler to produce cement. There is no discharge in the whole productive process. Resources and by-products in the productive process are reused efficiently to achieve the maximum utilization of resources.

The ECER system for this product includes Waste hydrochloric acid analytical technology (technology1), Waste sodium hypochlorite recycling technology (technology2), Variable pressure adsorption technology (technology3), Biochemical treatment technology on mother solution water (technology4), Acetylene recovery from slurry waste water (technology5) and Desulfurization technology of calcium carbide slag slurry (technology6). Among them, the technologies in the resource input stage is Tech. 1 and Tech. 2; the technologies in the resource utilization is Tech. 3 and Tech. 4; the technologies in the resource output stage is Tech. 5 and Tech. 6, as shown in Figure 4.

\subsection{The effects and value flow analysis of ECER technology}

\subsubsection{Effects and value flow analysis on water saving technologies}

(1)Waste sodium hypochlorite recycling technology (technology2) 
ECER effect. The technology is used to remove sulfur and phosphorus impurities in the process of acetylene purification and is more conducive to reduce the difficulty of sewage treatment, and the cost and amount of sewage. The environmental protection cost has been reduced so.

Value flow analysis. Reusing waste sodium hypochlorite decreases greatly water production. Daily water of 1000 tons is saved based on calculation of 130 thousand tons of PVC.

(2)Biochemical treatment technology on mother solution water (technology4)

Mother liquid water produced from PVC device is wastewater, which may be cycled for cooling transmission equipment, polymerization production and water production. It will save about 800 thousand tons water each year.

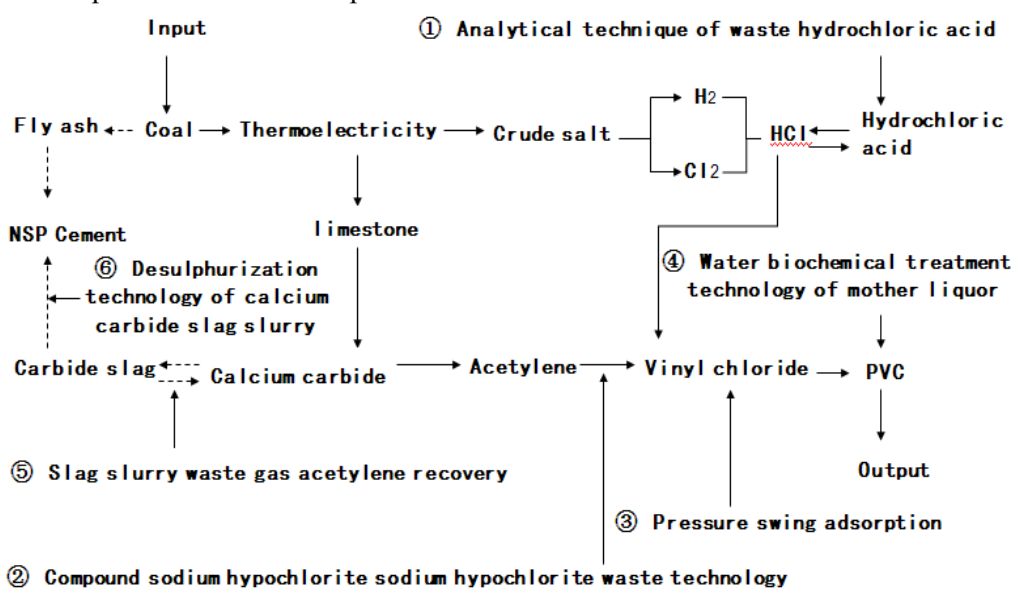

Figure 4. PVC production process and ECER technology system

\subsubsection{Effect and value flow analysis on waste gas recovery technology}

(1)Variable pressure adsorption technology (technology3)

ECER effect. Using the technology to recover vinyl chloride gas, acetylene gas and hydrogen in the tail gases, make the waste gas in effective recycling.

Value flow analysis. The hydrogen recycling may reduce power consumption in water electrolysis. 40,000 degrees electricity will be saved based on 8000 hours a year.

(2)Acetylene recovery from slurry waste water (technology5)

ECER effect. The acetylene gas dissolved in the waste water solution of calcium carbide slag slurry after reaction is recovered to cut the investment on the power equipment, and decrease other production medium for clean gas.

Value flow analysis. 3,000 tons calcium carbide consumption per year will be cut, and the original consumption of calcium carbide of 1.56 tons / per ton PVC is lowered to less than 1.45 ton / per ton PVC. In terms of economic efficiency, the annual 9 million Yuan will be cut, and 9,000 cubic meters of water may be saved.

\subsubsection{Effect and value flow analysis on solid waste comprehensive treatment technology}

(1)Desulfurization technology of calcium carbide slag slurry (technology6)

ECER effect. Carbide slag may be used for desulfurization in a heat and power plant, which and yellow phosphorus slag in the enterprise are reused for cement production, increasing greatly the comprehensive utilization amount of solid waste.

Value flow analysis. By the desulfurization technology of carbide slag slurry, the effect is obvious on the energy conservation, emission reduction, and resource recycling.

\subsubsection{Effect and value flow analysis on recycling and utilization of industrial by-products}

(1)Waste hydrochloric acid analytical technology (technology1)

ECER effect. It may prevent the production of industrial waste acid caused by the excessive proportion of hydrogen chloride in the production of vinyl chloride, and increase the economic value of recycling hydrogen chloride.

Value flow analysis. The annual reduction of sodium chloride is 6,000 tons, produces 2,100,000 Yuan economic benefits and the annual 12,3000 tons of water can be saved. 
The technology system of the above six technologies brought the comprehensive effect of ECER, including water saving, electricity conservation, reducing the amount of raw materials. By using the method of value flow analysis, the cost of water saving and electricity conservation may be obtained, and the economic benefits of these six technologies were obtained as shown in Table 2. From Table 2, we see that the ECER effect of technical system may bring about the economic value of up to 4.117 million Yuan. Among them, the largest contribution is the technology 6, the economic value of lime conservation is up to 3 million Yuan. The value flow of water saving is 61.4 thousand Yuan, involving four technologies, the largest contribution technology is technology 4, which saves water 800,000 tons per year, and the economic value is 37,900 Yuan.

Through technical cooperation between 2 and 4, it reduced sewage discharge and using water, and improves the utilization rate of circulating water. Through technology 5 and 3, it realized recycling of waste gas, and ECER. Through technology 6 and 1 , the reuse of wastes and by-products had been realized, and the additional economic value was created.

Technology 5 and 1 each had the dual synergistic effects of ECER or water saving and emission reduction. Technology 6 had only the energy-conservation and emission reduction synergies. The technology 3 had only power-conservation and emission reduction synergies, and had no synergistic effect with other technologies. According to table 2, the ECER collaborative evaluation table of the technical system of the energy intensive product was obtained as shown in table 3 .

From table 3 we see that, in the resource input stage, the synergistic effect of technology 1 is good, while the technology 2 is general. In the stage of resource utilization, the synergistic effect of technology 3 is poor, while the technology 4 is general. In the resource output stage, the synergistic effect of technology 5 is good, while the technology 6 is poor. Therefore, we obtain the result that the front control of technology system of the energy intensive product has a good synergistic effect, while the process control and the end control measures have general synergistic effect.

Table 2. Value flow analysis on ECER effect of the technology system

\begin{tabular}{|c|c|c|c|c|c|c|}
\hline NO. & $\begin{array}{l}\text { Technology } \\
\text { contribution }\end{array}$ & $\begin{array}{l}\text { Technology } \\
\text { Source }\end{array}$ & $\begin{array}{l}\text { Annual requirement } \\
\text { (tons) }\end{array}$ & $\begin{array}{c}\text { Standard coal } \\
\text { coefficient }\end{array}$ & $\begin{array}{l}\text { Standard coal } \\
\quad(\text { ton })\end{array}$ & $\begin{array}{l}\text { Cost } \\
\text { (Yuan) }\end{array}$ \\
\hline \multirow{4}{*}{1} & \multirow{4}{*}{ Water saving } & Technology 6 & 123,000 & \multirow{5}{*}{$0.0857 \mathrm{Kg} / \mathrm{t}$} & 11.7 & 5,800 \\
\hline & & Technology 1 & 365,000 & & 34.6 & 17,300 \\
\hline & & Technology 2 & 800,000 & & 75.8 & 37,900 \\
\hline & & Technology 4 & 9,000 & & 0.8 & 400 \\
\hline \multicolumn{3}{|c|}{ Sum } & $1,297,000$ & & 122.9 & 61,400 \\
\hline 2 & $\begin{array}{c}\text { Power } \\
\text { conservation }\end{array}$ & Technology 3 & 40,000 degrees & $0.329 \mathrm{Kg} / \mathrm{kW} \cdot \mathrm{h}$ & 13.16 & 6,600 \\
\hline 3 & $\begin{array}{l}\text { calcium } \\
\text { carbide }\end{array}$ & Technology 4 & 3,000 tons & - & 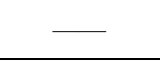 & $9,000,000$ \\
\hline 5 & lime & Technology 5 & 100,000 tons & $\bar{L}$ & $\bar{\square}$ & $30,000,000$ \\
\hline 6 & $\mathrm{NaCl}$ & Technology 6 & 6,000 tons & $\overline{-}$ & $\overline{-}$ & $2,100,000$ \\
\hline \multicolumn{6}{|c|}{ Sum } & $41,168,000$ \\
\hline
\end{tabular}

Table 3. Collaborative evaluation on ECER synergy of the technical system

\begin{tabular}{|c|c|c|c|c|}
\hline NO. & $\begin{array}{c}\text { Collaborative types of the } \\
\text { single technology }\end{array}$ & $\begin{array}{c}\text { Technology } \\
\text { collaboration }\end{array}$ & Judge result & Production process \\
\hline \multirow[b]{2}{*}{ Technology1 } & ECER & Yes & \multirow[b]{2}{*}{ Good synergy } & \multirow{3}{*}{$\begin{array}{l}\text { Resource input } \\
\text { stage }\end{array}$} \\
\hline & $\begin{array}{c}\text { Water saving and emission } \\
\text { reduction }\end{array}$ & Yes & & \\
\hline Technology2 & $\begin{array}{c}\text { Water saving and emission } \\
\text { reduction }\end{array}$ & Yes & General synergy & \\
\hline Technology3 & $\begin{array}{l}\text { Power conservation and } \\
\text { emission reduction }\end{array}$ & No & Poor synergy & \multirow{2}{*}{$\begin{array}{c}\text { Resource } \\
\text { utilization stage }\end{array}$} \\
\hline Technology4 & $\begin{array}{l}\text { Water saving and emission } \\
\text { reduction }\end{array}$ & Yes & General synergy & \\
\hline \multirow[t]{2}{*}{ Technology5 } & $\begin{array}{l}\text { Water saving and emission } \\
\text { reduction }\end{array}$ & Yes & \multirow{2}{*}{ Good synergy } & \multirow{3}{*}{$\begin{array}{l}\text { Resource output } \\
\text { stage }\end{array}$} \\
\hline & ECER & Yes & & \\
\hline Technology6 & ECER & No & Poor synergy & \\
\hline
\end{tabular}

Based on the conclusion that the end of pipe control measures had not synergistic effect, while the front control and process control measures had good synergistic effect (Mao Xianqiang, 2011), the technology2,3,4 and 6 remained to be improved in the production process of energy intensive products. To analysis further, technology 3 had not synergistic effect with other technology and its economic value was only $400 \mathrm{RMB}$, so it is necessary to seek for the replace technology. Technology 6 had poor synergistic effect, and has brought about economic value of 30,000,000 Yuan, while 
it is at the end of the production chain, so it may be limited to improve more. Water saving and emission reduction effect of technology 4 and technology 2 was remarkable. Technology 4 and technology 2 had good technical collaboration effect, and had produced inter-technology effect, so the two technologies were limited to improve further. Technology 6 and technology 3 have not had a synergistic effect with other technologies yet, it may have greater potential to improve the synergistic effect.

\section{Conclusions}

The ECER progress of an energy intensive enterprise depends on the ECER effect of the energy intensive products. ECER technology system construction of an energy intensive product is the main path and endogenous mechanism for enterprises to achieve ECER targets. Among them, the construction and implementation of the technical system in the production is the key factor. Technology system in production includes ECER technologies in three stages: resource input, resource utilization and product output. The synergistic effects of ECER technology system include two aspects: single technology and inter-technology, which may be summarized and calculated by the value flow analysis on each technology. This thesis tries to construct a 3D analysis model of ECER technology system and synergistic effects of an energy intensive product, and link the productive process, the position and effect of ECER technology. It will provide a useful method to analyze space arrangement, effectiveness regulation and coordinating control of ECER technology system. Through a case study for the application on an energy intensive product, we had taken in-depth analysis on the ECER system construction and the ECER effects achieved and the shortcomings in production, and some suggestions were given. The application results show that the three-dimensional analysis model will have a good theoretical and practical application value for in-depth study on the relationship between ECER technology system and ECER synergistic effect of an energy intensive product. The next step is to study further on improving the ECER technology system of an energy intensive product to optimize the ECER synergistic effects.

\section{References}

1. Martin, Chen Wenying. Analysis on the synergy effect of emission reduction technology in China's iron and steel industry. China Environmental Science, 35 (1): 298-303(2015)(in Chinese)

2. Mao Xianqiang, Zeng Eucalyptus. Evaluation on the coordinative control effect of sulfur, nitrogen and carbon of technical emission reduction measures in the steel industry. Environmental science, 32 (5):1253-1260(2012)

3. Xing Fangfang, Jiang Qi. Analysis on the cooperative control technology of multiple pollutants in sintering flue gas in iron and steel industry. Environmental engineering, (4): 75-78(2014)

4. Zhang Shuling, Zhu Guilin. Technological innovation, circular economy and ECER about comprehensive utilization of iron or steel slugs. The proceeding of the eighth annual meeting of China Iron and steel, 169-176(2011)

5. Han Yijie, Liu Xiuli. Eenergy efficiency and ECER potential of iron and steel industry in every regions of China based on super efficiency DEA model. System science and mathematics, 31 (3):287-298(2011)

6. Zeng Ping, Deng Tengzhi, Wu Xiaojie. ECER and technological innovation: from the enterprise experience in Guangdong Pearl River Delta region. Economic system reform, (1):108-111 (2013)

7. Li Li, Jianhui Wang. ECER policies for the electric power industry in China. Energy Policy, 39: 3669-3679(2011).

8. Zhaoguo Zhang, Xiaocui Jin. An empirical study on the institutional factors of energy conservation and emissions reduction: Evidence from listed companies in China. Energy Policy, 57: 36-42(2013).

9. Gao Yan, Zhang Ling. Performance evaluation of coal enterprises energy conservation and reduction of pollutant emissions base on GRD-TOPSIS. Energy Procedia, (5): 535-539(2011).

10. C.A.P. Pimenteira, A.S. Pereira. Energy conservation and $\mathrm{CO}_{2}$ emission reductions due to recycling in Brazil. Waste Management, (24): 889-897(2004).

11. Yan Linyu. Comprehensive analysis on material flow and value flow of Chinese iron resource. Chinese Geology University, Master Thesis, 2013

12. Mao Xianqiang, Zeng Eucalyptus. Study on the evaluation of the cooperative control effect of technical emission reduction measures. China Population, Resources and Environment, 21 (12): 1-7(2011) 